\title{
Experimental Research on Material Removal Mechanism and Grinding Force of FeCoNiCrMo0.1 High Entropy Alloy (HEA)
}

\author{
Ruchu Xu ( $\nabla$ xuruchu512@163.com ) \\ Northeastern University \\ Xuelong Wen \\ Northeastern University \\ Yadong Gong \\ Northeastern University \\ Xingchen Yu \\ Northeastern University
}

\section{Research Article}

Keywords: High entropy alloy, Material removal mechanism, Grinding debris, Microstructure, Grinding force

Posted Date: September 2nd, 2021

DOl: https://doi.org/10.21203/rs.3.rs-784381/v1

License: (9) This work is licensed under a Creative Commons Attribution 4.0 International License. Read Full License 


\title{
Experimental research on material removal mechanism and grinding force of FeCoNiCrMo 0.1 high entropy alloy(HEA)
}

\author{
Ruchu Xu Xuelong Wen* Yadong Gong Xingchen Yu \\ School of Mechanical Engineering and Automation, Northeastern University, Shenyang, China, 110819
}

\begin{abstract}
High entropy alloy (HEA) is an advanced alloy material, which has a wide application prospect due to its excellent properties. However, the material removal mechanism and change rule of grinding force of HEA in the grinding process have seldom been studied. The main work of this paper is that the material removal mechanism of the $\mathrm{FeCoNiCrMo} 0.1$ HEA is obtained by analyzing grinding debris and subsurface microstructure after grinding, the theoretical grinding force model of HEAs in plane grinding process is established on the basis of the force of a single abrasive grain, and the experimental verification is performed. According to the experimental results, the influences of different grinding parameters on grinding force are discussed, the influences of different types of grinding wheels on grinding force are analyzed, and the grinding forces generated by grinding different $\mathrm{FeCoNiCr}$ HEAs are compared. The results indicate that the material removal mechanism of FeCoNiCrMo 0.1 HEA is the plastic removal. With the increase of grinding speed and the decrease of grinding depth and feed speed, both normal and tangential grinding forces decrease. Under the same grinding parameters, the grinding force produced by electroplated CBN grinding wheel is greater, followed by resin-bonded CBN grinding wheel and vitrified CBN grinding wheel. The grinding force produced by grinding $\mathrm{FeCoNiCrAl}_{0.1}$ HEA is lower than that produced by grinding FeCoNiCrMo ${ }_{0.1}$ HEA under the same grinding conditions. The calculated value of grinding force model is consistent with the experimental value, which can scientifically reflect the variation law of HEA grinding force.
\end{abstract}

Key words: High entropy alloy; Material removal mechanism; Grinding debris; Microstructure; Grinding force

\section{Introduction}

The concept of high-entropy alloy (HEA) is formally proposed by Yeh et al. [1]. HEAs have more components compared with traditional alloys, and more new alloys can be developed by proper control of the element content. The HEA design concept has opened up new ideas for the development of alloy materials, which is known as one of the three breakthroughs in the concept of alloy design [2].

HEAs exhibit excellent mechanical properties and characteristics, such as high strength, high hardness, high wear resistance, high fracture toughness and superior radiation resistance [3-5]. Nhung et al. [6] obtained the nanoscale $\mathrm{Al}_{9}(\mathrm{CoCrFeMnNi})_{91}$ HEA composed of FCC and B2 phases through high

Corresponding author: Xuelong Wen

E-mail: wenxl@me.neu.edu.cn

Tel: +86-024-83687626 pressure torsional treatment. The grain refinement induced by high pressure torsion is combined with the finite grain growth during the thermoplastic deformation process. The super-plasticity of $2000 \%$ at high temperature $(1073 \mathrm{~K})$ and high strain rate $\left(5 \times 10^{-2}\right.$ $\mathrm{s}^{-1}$ ) was achieved by using the multi-phase ultra-fine grain structure. VNbMoTaW HEA [7] can maintain a yield strength of $477 \mathrm{MPa}$ at $1600^{\circ} \mathrm{C}$, while most traditional superalloys have a strength of less than 300 $\mathrm{MPa}$ at $1600^{\circ} \mathrm{C}$. The vacancy concentration of $\mathrm{Ti}_{2} \mathrm{ZrHfV}_{0.5} \mathrm{Mo}_{0.2}$ HEA designed by Lu et al. [8] was higher than that of conventional alloys, its lattice constant after irradiation decreased, and radiation hardening phenomenon hardly happened. The found indicated this HEA had a high radiation resistance.

In recent years, as HEAs show practical 
application prospects, the research on machining of HEAs has been reported gradually. George et al. [9] conducted milling experiments comparing $\mathrm{Al}_{0.6} \mathrm{FeCoNiCr} \mathrm{HEA}$ with 304 stainless steel. Their experimental results indicated that the machinability of this HEA was about 59\% better than 304 stainless steel. Przemyslaw et al. [10] carried out milling experiments on FeCoNiCrMn HEA blocks prepared by selective laser melting technology. The experimental results showed that the machinability of this HEA was better than AISI 304L stainless steel. Gong et al. [2] performed a series of micro-grinding experiments on $\mathrm{Fe}_{40} \mathrm{Mn}_{40} \mathrm{Co}_{10} \mathrm{Cr}_{10}$ and $\mathrm{FeCoCrNiMn}$ HEAs, and studied the influences of different grinding parameters on the surface quality and micro-grinding force of HEAs under micro-grinding conditions. In recent years, there has been little research on the machining of HEAs, especially the grinding process of HEAs, and there is no systematic research at present.

In this paper, the plane grinding experiments of FeCoNiCrMo ${ }_{0.1}$ HEA were carried out. Based on the analysis of the morphology of grinding debris and the microstructure of the grinding subsurface, the removal mechanism of FeCoNiCrMo 0.1 HEA is obtained. The theoretical model of grinding force of HEA is established and verified by experiments, and the influence of different grinding parameters on the grinding force is analyzed, the influence of different kinds of grinding wheels on the grinding force is studied, and the influencing factors and characteristics of the grinding force of two kinds of HEAs are compared, which provide the theoretical and experimental basis for the grinding processing of HEA parts.

\section{Material removal mechanism analysis of FeCoNiCrMo ${ }_{0.1}$ HEA}

\subsection{Grinding debris analysis}

The formation of grinding debris marks the realization of the grinding process. The analysis of grinding debris morphology is significant to understand the material removal mechanism of $\mathrm{FeCoNiCrMo}{ }_{0.1} \mathrm{HEA}$.
Scanning electron microscopy was used to observe the grinding debris morphology. It can be seen from Fig.1, there are great differences in the size, morphology and color of the grinding debris collected by many groups of experiments, which indicates that the material removal state under different machining parameters is different in the grinding process. The contact status between the abrasive grain and the specimen is continually changing with the change of grinding parameters, leading that the morphology and size of the grinding debris are diverse.

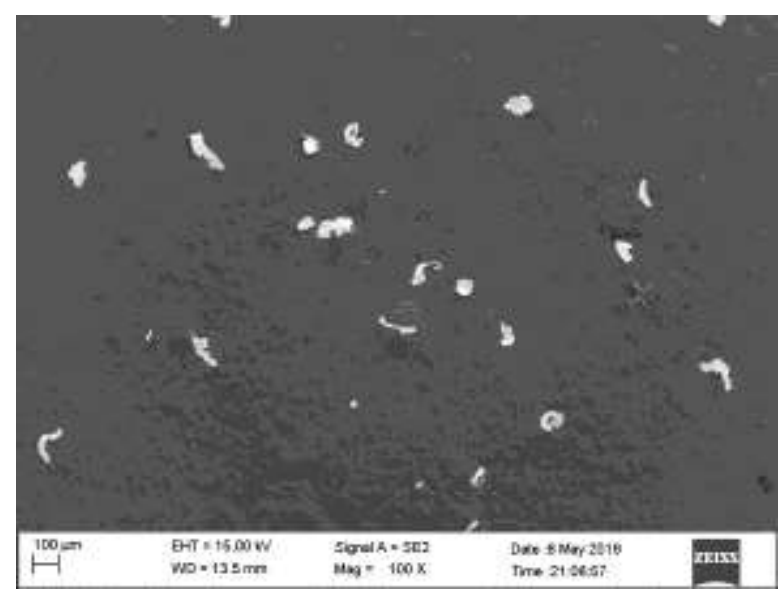

Fig .1 Grinding debris morphology under different machining parameters

Fig.2 shows the contact and free surface morphology of grinding debris. As shown in Fig.2, the contact surface of grinding debris is relatively smooth and has uniform plastic grinding marks, and the free surface of grinding debris appears the sawtooth pitches caused by the action of extrusion and shearing in the grinding process. The severe plastic shear slip deformation mainly occurs in the narrow area between the adjacent sawtooth pitches, while the shear slip deformation in the sawtooth pitch area is very small, thus the inside of the area is relatively flat. In the grinding process, the sawtooth pitches appear on the free surface of grinding debris and expand periodically with the feed of the specimen, causing that the free surface of the grinding debris presents the characteristic of serrated morphology. 

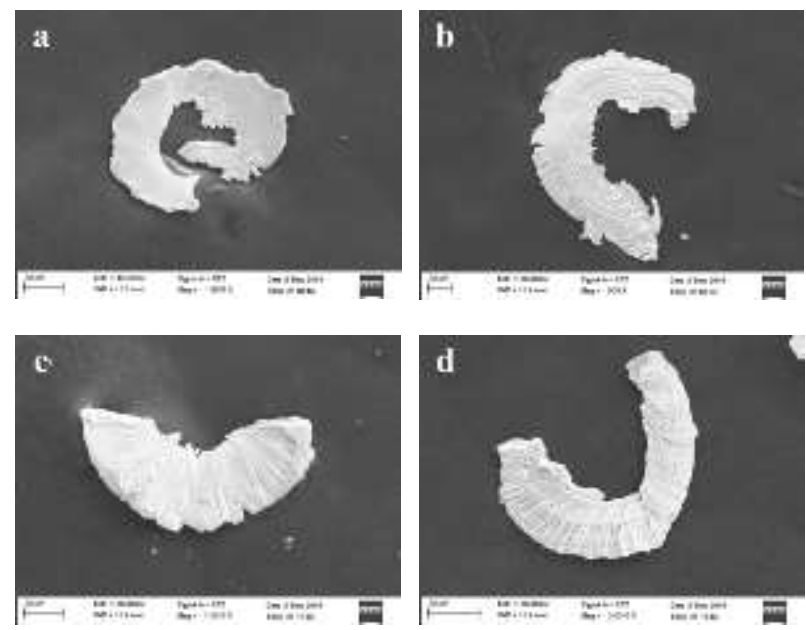

Fig.2 Contact and free surface morphology of grinding debris. a and $\mathbf{b}$ Contact surface. $\mathbf{c}$ and $\mathbf{d}$ Free surface

In order to clearly reflect the morphology characteristics of the grinding debris, the typical grinding chips were selected for observation and analysis. Depending on the frequency of occurrence, there are mainly two kinds of grinding debris of $\mathrm{FeCoNiCrMo}_{0.1}$ HEA: banded grinding debris and block grinding debris.

Banded grinding debris is shown in Fig.3. As shown in Fig.3, the bending deformation degree of banded grinding debris is larger, the side of grinding debris is smoother, and few cracks appear on the edge of debris. In the experiments, it can be obviously found that the banded grinding debris is easy to be produced when the grinding depth is smaller. At this time, the grinding process is smoother, the fluctuation of grinding force is smaller, and the serrated features generated on the free surface of the grinding debris are finer. With the increase of grinding depth, the banded grinding debris would become less and less.
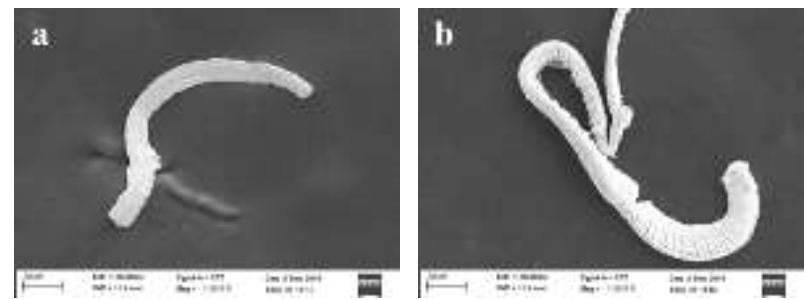

Fig.3 Banded grinding debris.a Contact surface. b Free surface

Fig. 4 is the photograph of block grinding debris. Because of many voids inside the casting HEA, micro-cracks gradually form and propagate at the void edge under the action of large grinding force. Under the joint action of external mechanical loads and internal cracks, the specimen materials are easy to be peeled off from the matrix and then form massive grinding debris. When the grinding wheel passes through the specimen, plastic deformation generates on the surface of the specimen due to the extrusion between the grinding wheel and the specimen. Because the hardness of FeCoNiCrMo ${ }_{0.1}$ HEA is high and the plastic deformation duration is short, so the specimen materials have been removed and separated from the specimen before the maximum plastic deformation is reached, thus the whole grinding debris does not occur large bending deformation. The block grinding debris is generally generated when the grinding depth is larger. At this moment, the thickness of grinding chip is larger, the grinding force is higher, and the pitch of the serrated feature is obviously larger than that of the banded grinding debris.
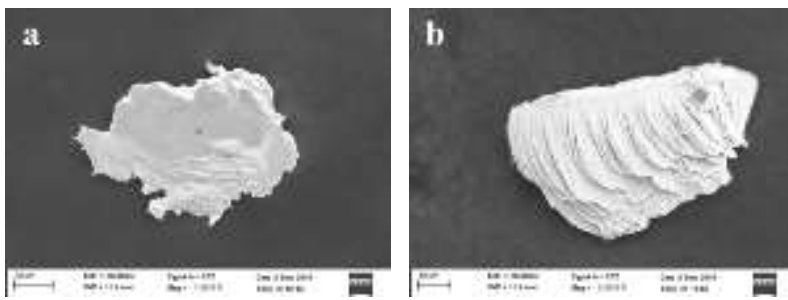

Fig.4 Block grinding debris. a Contact surface. b Free surface

According to the research [11], the serrated characteristic is the typical mark of the plastic removal. Therefore, it can be deduced that $\mathrm{FeCoNiCrMo}_{0.1}$ HEA conforms to the mechanism of plastic material removal.

\subsection{Grinding subsurface microstructure analysis of FeCoNiCrMo . $_{0.1}$ HEA}

Fig.5 shows the crystal phase structure of the matrix. It can be seen from Fig.5, the phase structure of the matrix is typical dendrite structure and has the homogeneous arrangement. In addition, many micro-voids are randomly distributed in the matrix of casting HEA. Under the action of large external force, micro-cracks are easily generated at the edge of voids, resulting in damage of the matrix. 

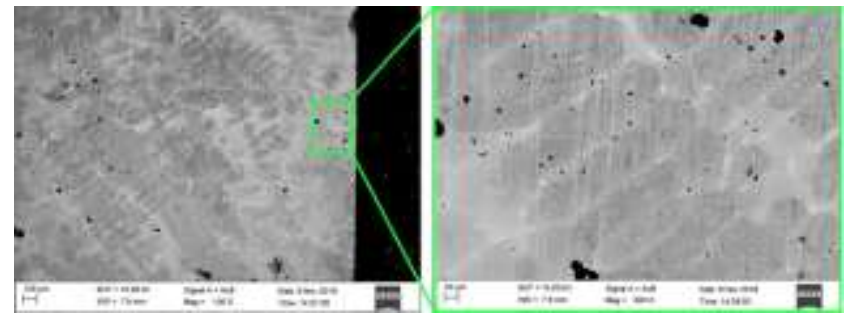

Fig.5 Microstructure morphology of the matrix

The subsurface microstructure morphology after grinding is shown in Fig.6. The structure of subsurface layer is significantly different from the structure of the matrix. The dense work hardening layer is formed near the grinding surface, which has finer grains, denser internal structure and higher hardness than the matrix. This is because the sliding, ploughing and cutting action of the abrasive grains during grinding process cause the corresponding plastic deformation of the subsurface layer of the specimen, distort the lattice, and shatter the grain, increasing the surface hardness of the specimen. Meanwhile, dislocation movement inevitably occurs in the subsurface when the specimen is deformed. The interaction between the dislocations of the sliding systems and the formation of defects jointly cause the accumulation of dislocations, which greatly increases the deformation resistance, and also leads to the work hardening phenomenon on the grinding surface.

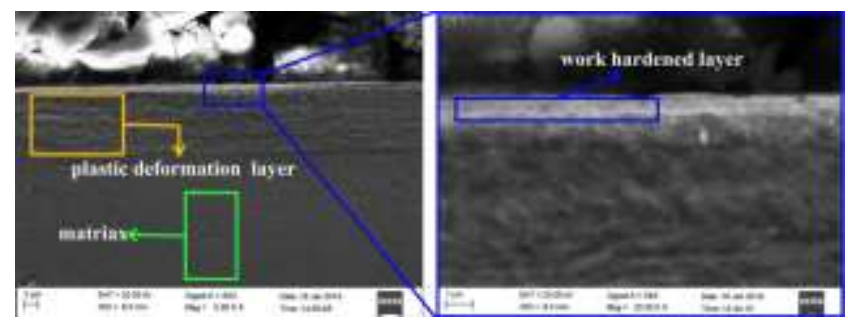

Fig.6 Grinding subsurface microstructure morphology

XRD phase analysis was conducted on $\mathrm{FeCoNiCrMo}_{0.1}$ HEA samples obtained at grinding depths of $0 \mu \mathrm{m}, 20 \mu \mathrm{m}$ and $80 \mu \mathrm{m}$. Fig. 7 shows the XRD analysis results. This HEA mainly contains $\mathrm{Ni}_{3} \mathrm{Fe}$ and other compounds before grinding, and $\mathrm{Ni}_{2.9} \mathrm{Cr}_{0.7} \mathrm{Fe}_{0.6}$ is generated in the work hardening layer after grinding. With the grinding depth increases, the diffraction peak of $\mathrm{Ni}_{2.9} \mathrm{Cr}_{0.7} \mathrm{Fe}_{0.6}$ phase has a tendency to become stronger. It indicates that the grinding temperature of the HEA reaches the phase transition temperature and the microstructure of the surface/surface material has changed.

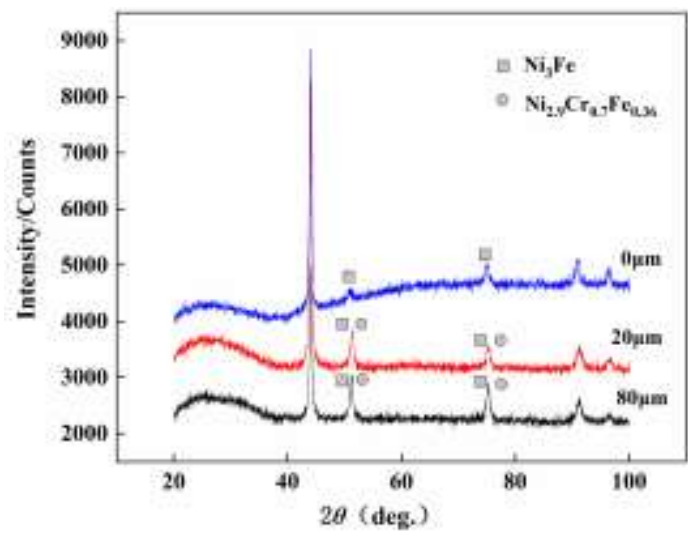

Fig.7 XRD analysis results of FeCoNiCrMo 0.1 HEA

Fig.8 shows the microstructure of the plastic deformation layer after grinding. It can be seen from Fig. 8 that the microstructure of the plastic deformation layer is dendrite structure, and white particles are dispersed on the plastic deformation layer. In the range of about $10 \mu \mathrm{m}$ below the grinding surface, the microstructure has serious distortion along the grain boundary. The reason is that the microstructure has serious plastic shear slip under the action of grinding force and grinding heat. The subsurface microstructure has serious deformation along the grinding direction, which is obviously different from the microstructure of the matrix. The lattice has dislocation and distortion, the slips among grains occur, and the grains are stretched. As the grinding proceeds further, the grinding force and the plastic strain of the grinding surface increase, and substructure inside the HEA grains change. The dislocation entanglement phenomenon develops further, and the grains are broken into finer sub-grains. It indicates that finer grain structure is formed in the work hardening layer, as shown in Fig.6.
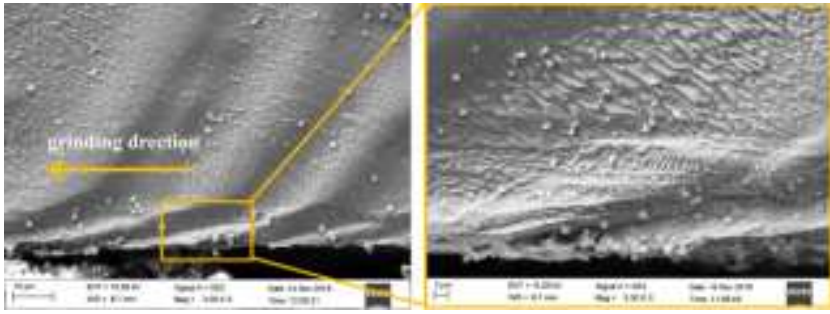

Fig.8 Grinding microstructure morphology of plastic deformation layer

Plastic deformation and work hardening are important characteristics in material plastic removal 
process. Combined with the observation and analysis of the grinding debris morphology, it can be concluded that the material removal mechanism of $\mathrm{FeCoNiCrMo}_{0.1}$ HEA is plastic removal mode in the grinding conditions.

\section{Theoretical model of grinding force of HEA}

The grinding force is caused by the elastic deformation, plastic deformation, debris formation and friction between the grinding wheel and the specimen during the grinding process, which has a great impact on the service life of the grinding wheel, the machined surface quality of the specimen and the deformation of the machining system. Therefore, establishing an effective mathematical model of grinding force of HEA has high theoretical significance and application value, which can provide an important theoretical basis for studying the grinding mechanism of HEA.

\subsection{Maximum undeformed chip thickness}

The maximum undeformed chip thickness is an important physical quantity in the investigation of material removal mechanism. Generally, the section of the undeformed chip include triangular section, rectangular section and trapezoidal section. In order to simplify the calculating process, the chip thickness is regarded as a rectangular. The interference between the single abrasive grain and the specimen is shown in Fig.9. The maximum undeformed chip thickness $h_{\max }$ can be expressed as

$h_{\max }=\left(\frac{3}{C \tan \theta}\right)^{1 / 2}\left(\frac{v_{w}}{v_{s}}\right)^{1 / 2}\left(\frac{a_{p}}{d_{e}}\right)^{1 / 4}$

Where, $C$ is the number of effective abrasive grains in per unit area on grinding wheel; $\theta$ is the half angle of diamond abrasive tip cone or indenter head; $v_{w}$ is the workpiece feed speed; $v_{s}$ is the grinding speed; $d_{s}$ is the equivalent diameter of grinding wheel; $a_{p}$ is the grinding depth.

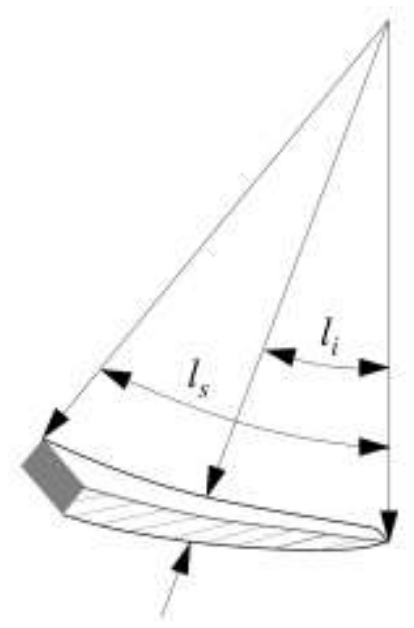

Fig.9 Interference between the single abrasive grain and specimen

\subsection{Dynamic contact arc length}

In the actual grinding process, the geometric contact arc length has great limitations and is difficult to reflect the grinding situation correctly. However, the dynamic contact arc length is close to the actual contact arc length, so the concept of dynamic contact arc length is introduced to make the theoretical model more close to the actual grinding process and improve the validity of the model. The formula of dynamic contact arc length can be expressed as

$l_{s}=\left(1 \pm \frac{v_{w}}{v_{s}}\right) \sqrt{d_{s} a_{p}}$

\subsection{The number of effective abrasive grains}

To facilitate the calculation, assuming that the abrasive grains are spherical grains with diameter $d_{g}$ and are uniformly distributed in the grinding wheel. The volume fraction of abrasive grains in the grinding wheel is $V_{g}$, and the number of abrasive grains contained in unit volume is

$N=\frac{6 V_{g}}{\pi d_{g}^{3}}$

It is assumed that on average $1 / 4$ volume of effective abrasive grains is exposed to the surface of the grinding wheel. There is only one effective cutting edge for each exposed the abrasive grains. The number of effective grinding edges per unit area on the surface of the grinding wheel can be expressed as 


$$
N_{\mathrm{d}}=4 N h
$$

Where, $\mathrm{h}$ is the grinding thickness. When the average grinding thickness of the single abrasive grain is set as $h_{\max } / 2$, the effective average number of abrasive edges per unit area can be expressed as

$$
C=2 N h_{\max }
$$

Substituting Eq.(5) into Eq.(1) can obtain the maximum undeformed chip thickness, which can be expressed as

$$
h_{\max }=\left(\frac{3}{2 N \tan \theta}\right)^{1 / 2}\left(\frac{v_{w}}{v_{s}}\right)^{1 / 2}\left(\frac{a_{p}}{d_{e}}\right)^{1 / 4}
$$

\subsection{Establishment of grinding force model of HEA}

In the actual grinding process, grinding force consists of cutting deformation force and friction force. The grinding model of single diamond abrasive grain with top cone angle $2 \theta \geq 90^{\circ}$ is established. The normal grinding force $F_{g n}$ and tangential grinding force $F_{g t}$ of the single abrasive grain can be expressed as

$$
\left\{\begin{array}{l}
F_{g n}=F_{g n c}+F_{g n s} \\
F_{g t}=F_{g t c}+F_{g t s}
\end{array}\right.
$$

Where, $F_{g n c}$ is the normal grinding force generated by the chip deformation of the single abrasive grain; $F_{\text {gns }}$ is the normal grinding force caused by friction between the single abrasive grain and the specimen. $F_{g t c}$ is the tangential grinding force caused by chip deformation of the single abrasive grain. $F_{\text {gts }}$ is the tangential grinding force caused by friction between the single abrasive grain and the specimen.

For the single abrasive grain, the tangential grinding force $F_{g t s}$ and the normal grinding force $F_{g n s}$ caused by friction are

$$
\left\{\begin{array}{c}
F_{g n s}=\delta \bar{p} \\
F_{g t s}=\mu \overline{\delta p}
\end{array}\right.
$$

Where, $\delta$ is the contact area of the single effecting abrasive grain; $\bar{p}$ is the average contact pressure between the specimen and the abrasive wear plane; $\mu$ is the friction coefficient between the specimen and the wear plane of the single abrasive grain.

According to the binomial law of friction, the coefficient of friction is

$\mu=\frac{\alpha A_{0}}{W}+\beta=\frac{\alpha}{\bar{p}}+\beta$

Where $\alpha$ and $\beta$ are determined by the physical and mechanical properties of the friction surface, respectively.

According to measurement theory of vickers hardness and indentation feature size of material hardness, the load can be expressed as

$p=\zeta H a^{2}$

Where, $p$ is the mechanical load; $a$ is the indentation size; $\zeta$ is the geometric factor of the indenter, and $\zeta=2$ for the Vickers indenter.

Fig.10 shows the feature size of indentation, which can be expressed as

$$
2 a=2 h \tan \theta
$$

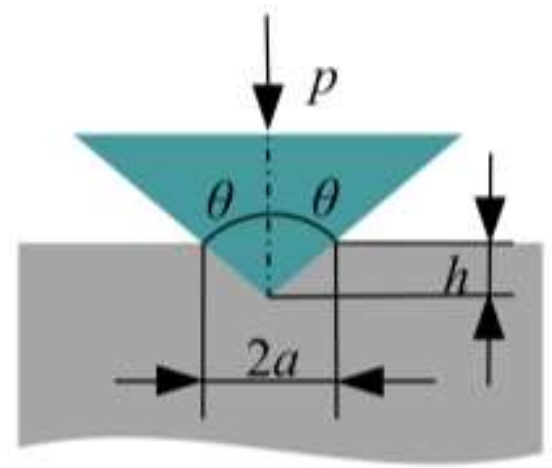

Fig.10 Schematic diagram of indentation of the single abrasive grain

Under the condition of pure shear deformation, the normal grinding force $F_{g n c}$ of the single abrasive grain caused by chip deformation is

$$
F_{g n c}=\eta_{0} \zeta \tan ^{2} \theta H h^{2}
$$

Where, $\eta_{0}$ is a constant between 0 and 1 .

Under the condition of pure shear deformation, the tangential grinding force $F_{g t c}$ of the single abrasive grain caused by chip deformation is

$$
F_{g t c}=\frac{\pi}{4 \tan \theta} \cdot F_{g n c}=\frac{\pi}{4} \eta_{0} \zeta \tan \theta H h^{2}
$$

Therefore, the formulas for calculating the normal 
grinding force $F_{g n}$ and tangential grinding force $F_{g t}$ of the single abrasive particle are as follows

$$
\left\{\begin{array}{c}
F_{g n}=F_{g n c}+F_{g n s}=\eta_{0} \zeta \tan ^{2} \theta H h^{2}+\delta \bar{p} \\
F_{g t}=F_{g t c}+F_{g t s}=\frac{\pi}{4} \eta_{0} \zeta \tan \theta H h^{2}+\mu \overline{\delta p}
\end{array}\right.
$$

According to the geometric relation $h \approx h_{\max } l_{i} / l$, the formulas (15) can be obtained by replacing $h$.

$$
\left\{\begin{array}{c}
F_{g n}=\eta_{0} \zeta \tan ^{2} \theta H\left(\frac{h_{\max }}{l} l_{i}\right)^{2}+\delta \bar{p} \\
F_{g t}=\frac{\pi}{4} \eta_{0} \zeta \tan \theta H\left(\frac{h_{\max }}{l} l_{i}\right)^{2}+\mu \delta \bar{p}
\end{array}\right.
$$

The normal grinding force and tangential grinding force on the unit grinding width are equal to the sum of the normal and tangential forces of all effective abrasive grains on the unit grinding width of the specimen and the contact surface of the grinding wheel respectively, which can be expressed as

$$
\left\{\begin{array}{l}
F_{n}^{\prime}=\int_{0}^{l_{s}} F_{g n} N_{d} d l_{i} \\
F_{t}^{\prime}=\int_{0}^{l_{s}} F_{g t} N_{d} d l_{i}
\end{array}\right.
$$

The calculation formulas of grinding force on unit grinding width of grinding wheel and specimen during plane grinding are expressed as

$$
\left\{\begin{array}{c}
F_{n}^{\prime}=\eta_{0} \zeta \tan ^{2} \theta H h_{\max }^{3} l_{s}+2 N \delta \bar{p} h_{\max } l_{s} \\
F_{t}^{\prime}=\frac{\pi}{4} \eta_{0} \zeta \tan \theta H h_{\max }^{3} l_{s}+2 \mu N \delta \bar{p} h_{\max } l_{s}
\end{array}\right.
$$

It can be seen from formula (17) that the grinding force increases with the increase of the material hardness and the top cone angle of the abrasive grain, but decreases with the increase of the diameter of the grinding wheel. When the material parameters of the specimen and the characteristic parameters of the grinding wheel are determined, the grinding force increases with the grinding depth and feed speed, and decreases with the grinding speed.

\section{Experiment on grinding force of FeCoNiCrMo 0.1 HEA}

\subsection{Experimental conditions and scheme}

\subsubsection{Experimental materials and equipment}

The experimental materials were $\mathrm{FeCoNiCrMo}_{0.1}$ and $\mathrm{FeCoNiCrAl}_{0.1}$ casting HEAs. Fig.11 is the component detection diagrams of the two HEAs.
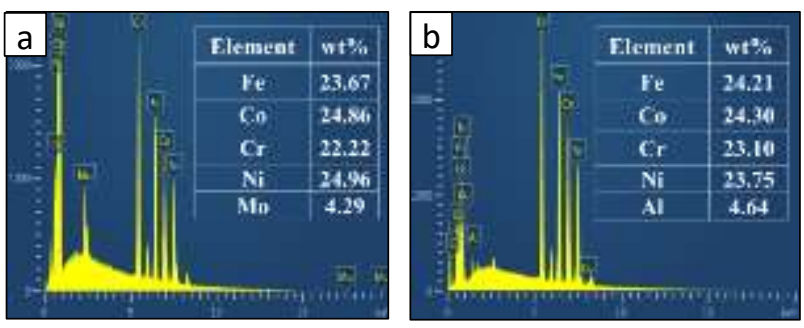

Fig.11 Diagram of component detection. a $\mathrm{FeCoNiCrMo}_{0.1}$ HEA. b FeCoNiCrAl $\mathrm{F}_{0.1}$ HEA

The 2M9120 plane grinding machine was adopted as the machining equipment in the experiments. Kistler three-direction dynamometer was adopted as the grinding force testing equipment. The resin-bonded CBN grinding wheel, electroplated CBN grinding wheel and vitrified CBN grinding wheel with the same parameters were adopted as the experimental grinding wheel. The width of grinding wheels is $6 \mathrm{~mm}$, grain size is $120 \#$, and diameter is $180 \mathrm{~mm}$. The experimental working table is shown in Fig.12.

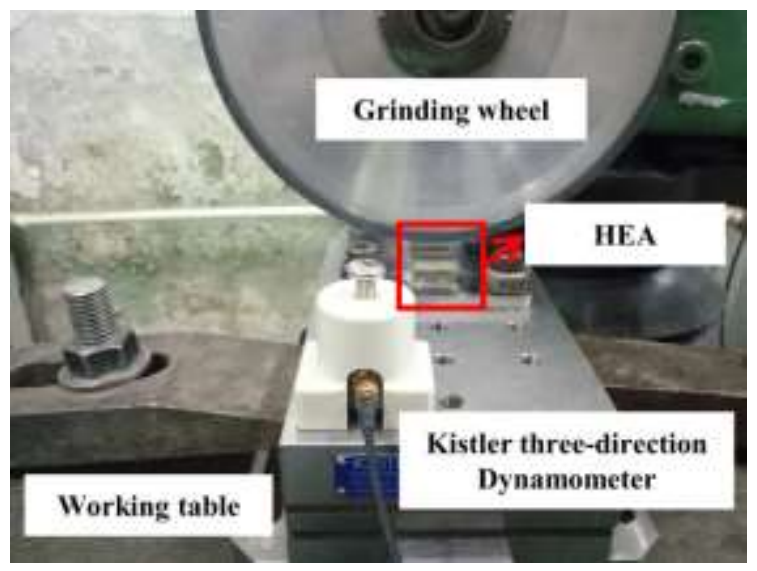

Fig.12 Working table of grinding experiment

\subsubsection{Experimental design scheme}

Resin-bonded CBN grinding wheel, electroplated CBN grinding wheel and vitrified $\mathrm{CBN}$ grinding wheel were used to carry out three-factor and five-level orthogonal grinding experiments on $\mathrm{FeCoNiCrMo}_{0.1}$ and $\mathrm{FeCoNiCrAl}_{0.1}$ HEAs, respectively. The influences of feed speed $v_{w}$, grinding speed $v_{s}$ and grinding depth $a_{p}$ on grinding force and surface roughness were analyzed. Tab.1 shows the 
orthogonal experimental scheme.

Table 1 Orthogonal experimental scheme

\begin{tabular}{crlllll}
\hline Grinding factors & \multicolumn{6}{c}{ Level value } \\
\hline$v_{w} /\left(\mathrm{m} \cdot \mathrm{min}^{-1}\right)$ & 0.45 & 0.60 & 0.75 & 0.90 & 1.05 \\
$a_{p} /(\mu \mathrm{m})$ & 30 & 40 & 50 & 60 & 70 & 80 \\
$v_{s} /\left(\mathrm{m} \cdot \mathrm{s}^{-1}\right)$ & 13 & 15 & 18 & 20 & 23 & 25 \\
\hline
\end{tabular}

Single factor experiments of $\mathrm{FeCoNiCrMo}_{0.1} \mathrm{HEA}$ were conducted by using resin-bonded $\mathrm{CBN}$ grinding wheel. The theoretical values of grinding force model and single factor experimental values of grinding process at different grinding speed $v_{s}$ and grinding depth $a_{p}$ are compared to verify the accuracy of the grinding force model of HEA. The experimental scheme is shown in Tab.2.

Table 2 Single factor experimental scheme

\begin{tabular}{crrrrrrr}
\hline Grinding parameter & \multicolumn{8}{c}{ Parameter value } \\
\hline$v_{w} /\left(\mathrm{m} \cdot \mathrm{min}^{-1}\right)$ & 5 & 10 & 20 & 30 & 40 & 50 & 60 \\
$a_{p} /(\mu \mathrm{m})$ & & 13 & 15 & 20 & 25 & 30 & \\
$v_{s} /\left(\mathrm{m} \cdot \mathrm{s}^{-1}\right)$ & &
\end{tabular}

\subsection{Experimental results and discussion}

\subsubsection{Influence law of different grinding parameters on grinding force}

Fig.13 shows the influence of feed speed on grinding force in grinding process of $\mathrm{FeCoNiCrMo}{ }_{0.1}$ HEA with resin-bonded CBN wheel. It can be seen from Fig.13, with the feed speed increasing, both the tangential and normal grinding forces have a trend of gradual increase, and the normal grinding force is always higher than the tangential grinding force. This is because the contact arc length between the grinding wheel and the specimen increases with the increase of feed speed, the undeformed chip thickness of a single abrasive grain increases, and the grinding debris become thicker, thus the material removal amount in per unit time increases. Therefore, the grinding force also increases. Moreover, with the increase of feed speed, grinding debris are not discharged by grinding whee in time, the grinding debris is easy to adhere to grinding wheel and block the gap among abrasive grains, so that the friction between the grinding wheel and the specimen is enhanced, resulting in the increase of grinding force. Fig.14 is the grinding surface morphology by using resin-bonded $\mathrm{CBN}$ grinding wheel at different feed speeds. When the feed speed is $0.45 \mathrm{~m} / \mathrm{min}$, the grinding surface is relatively smooth and has shallow grinding marks. With the feed speed increasing, the grinding surface becomes rough, and deeper grinding marks and a few pits occur on the grinding surface. In consequence, the grinding force can be reduced and the surface quality can be improved by appropriately reducing the feed speed in grinding the HEA procedure.

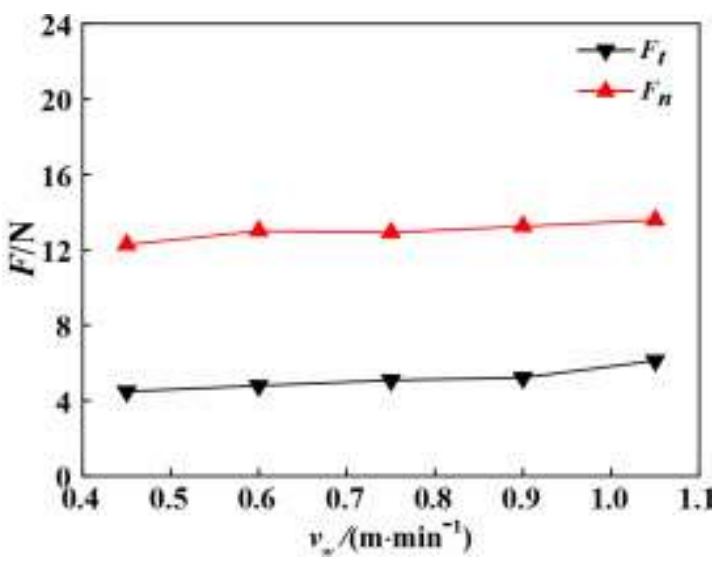

Fig.13 Effect of feed speed on grinding force of $\mathrm{FeCoNiCrMo}_{0.1}$ HEA
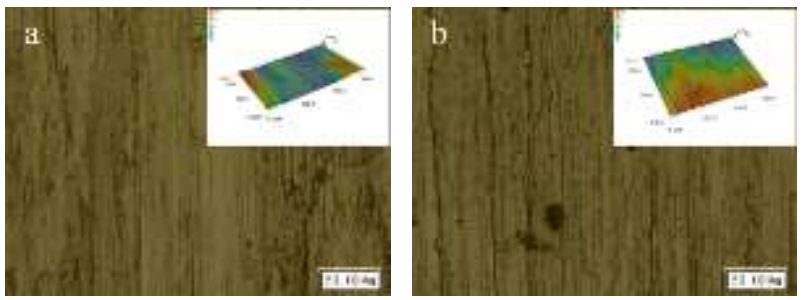

Fig.14 Grinding surface topography at different feed speeds. a $v_{w}=0.45 \mathrm{~m} / \mathrm{min}$. b $v_{w}=1.05 \mathrm{~m} / \mathrm{min}$

Fig.15 is the influence of grinding speed on grinding force of $\mathrm{FeCoNiCrMo}_{0.1} \mathrm{HEA}$ with resin-bonded $\mathrm{CBN}$ grinding wheel. As the grinding speed increases, the tangential and normal grinding forces both show a decreasing trend, and the normal grinding force is higher than the tangential grinding force all the time. It is mainly because, the increasing grinding speed increases the number of abrasive grains involved in grinding in per unit time, and the number of abrasive grain removing material increases, causing that the thickness of the undeformed chip of a single abrasive grain decreases. Therefore, the grinding debris becomes thinner, and the grinding force of a single abrasive grain decreases. However, as 
grinding speed further becomes larger and larger, when it gradually approaches or exceeds the propagation speed of plastic deformation of the HEA, the specimen material is removed with slight deformation by abrasive grains, and most of the grinding heat is taken away by grinding debris. The thermal softening effect is weakened, and the trend of reduction is slowed down. Fig.16 shows the grinding surface morphology with resin-bonded CBN grinding wheel under different grinding speeds. The grinding marks are deep, and some pits are produced on grinding surface when the grinding speed is $10 \mathrm{~m} / \mathrm{s}$. With the grinding speed increasing, the grinding marks on the surface are obviously shallower, and the number of pits is remarkably reduced, and the surface quality is better. Therefore, the grinding force can be reduced and the surface quality can be improved by properly increasing the grinding speed in the grinding the HEA process.

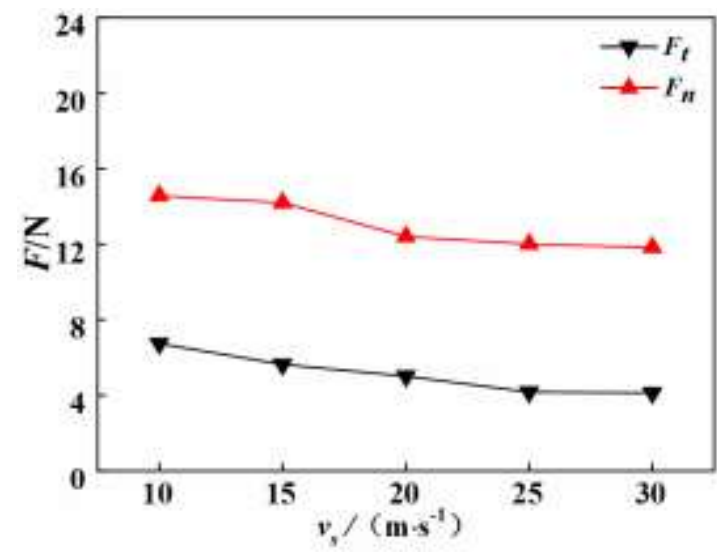

Fig.15 Effect of grinding speed on grinding force of $\mathrm{FeCoNiCrMo}_{0.1} \mathrm{HEA}$
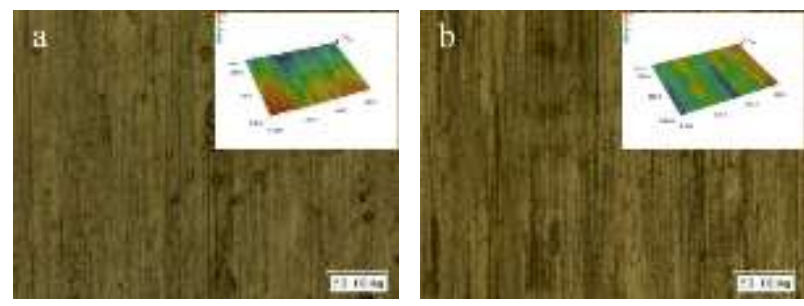

Fig.16 Grinding surface morphology at different grinding speeds. a $v_{s}=10 \mathrm{~m} / \mathrm{s}$. b $v_{s}=30 \mathrm{~m} / \mathrm{s}$

The influence of grinding depth on grinding force in grinding $\mathrm{FeCoNiCrMo}_{0.1}$ HEA with resin-bonded CBN grinding wheel is shown in Fig.17. It can be seen from Fig.17, with the increase of grinding depth, both the tangential and normal grinding forces increase, and the normal grinding force is higher than the tangential grinding force. The reason is that the material removal amount of a single abrasive grain increases with the continuous increase of grinding depth, the thickness of undeformed chip of a single abrasive grain increases, and the grinding debris becomes thicker, thus the grinding force of a single abrasive grain increases. Furthermore, $\mathrm{FeCoNiCrMo}_{0.1}$ HEA has a high strain hardening rate, and the phenomenon of cold work hardening on the machined surface becomes more significant with the further increase of grinding depth. The increase of surface hardness makes material removal become difficult, the material removal amount of a single abrasive grain decreases, and the grinding force increases. Fig. 18 shows the grinding surface morphology of the HEA with resin-bonded CBN grinding wheel at different grinding depths. When the grinding depth is $5 \mu \mathrm{m}$, the grinding surface is relatively flat and has a than uniform distribution of grinding marks. With the increase of grinding depth, the depth of grinding marks increases obviously, the distribution of grinding marks is gradually uneven, and many pits occur on the surface. In the actual machining process, the grinding depth can be appropriately lowered to reduce grinding force and improve surface quality.

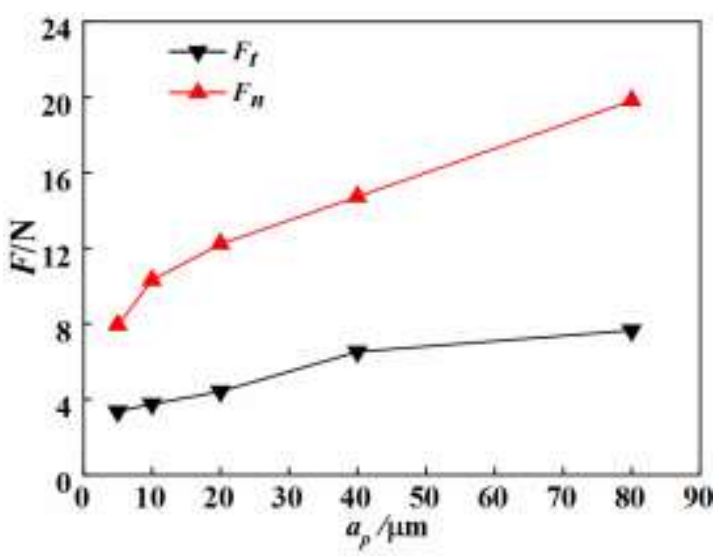

Fig.17 Effect of grinding depth on surface roughness of $\mathrm{FeCoNiCrMo} 0.1$ HEA 

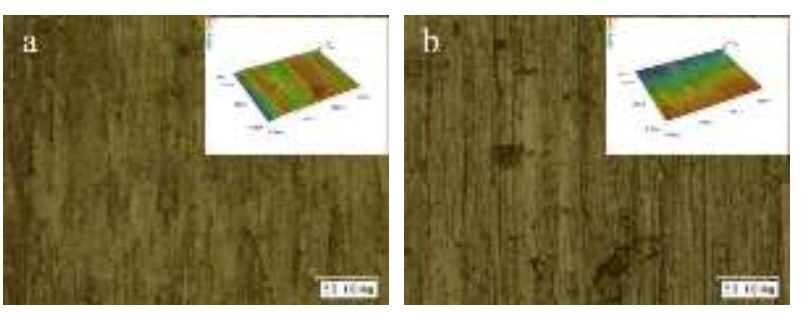

Fig.18 Grinding surface morphology at different grinding depths. a $a_{p}=20 \mu \mathrm{m}$. $\mathrm{b} a_{p}=80 \mu \mathrm{m}$

\subsubsection{Influence law of different grinding wheels on grinding force}

Fig.19 is the comparison of grinding forces after grinding $\mathrm{FeCoNiCrMo} \mathrm{O}_{0.1}$ HEA by electroplated $\mathrm{CBN}$ grinding wheel, resin-bonded CBN grinding wheel and vitrified CBN grinding wheel at different feed speeds. It can be seen from Fig.19 that the tangential and normal grinding forces generated by the three types of grinding wheels increase with feed speed increasing. Under the same grinding parameters, the tangential and normal grinding forces generated by electroplated CBN grinding wheel is greater, followed by resin-bonded $\mathrm{CBN}$ grinding wheel and vitrified CBN grinding wheel.

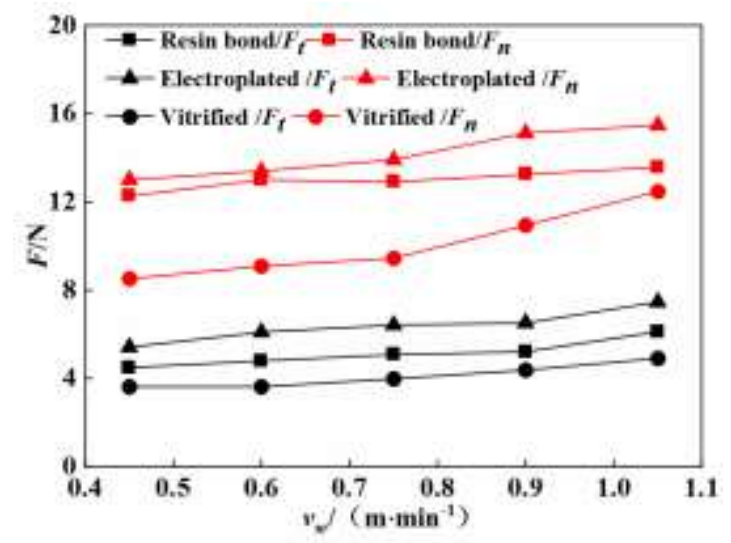

Fig.19 Effect of grinding wheels on grinding force at different feed speeds

Fig.20 shows the comparison of grinding forces by electroplated CBN grinding wheel, resin-bonded CBN grinding wheel and vitrified CBN grinding wheel at different grinding speeds. As shown in Fig.20, the tangential and normal grinding forces produced by the three kinds of grinding wheels all decrease with the increase of the grinding speed. When the grinding parameters are same, the grinding force produced by electroplated CBN grinding wheel is still greatest and the grinding force produced by vitrified $\mathrm{CBN}$ grinding wheel is smallest, and the grinding force produced by the resin-bonded $\mathrm{CBN}$ grinding wheel is slightly lower than that of the electroplated CBN grinding wheel.

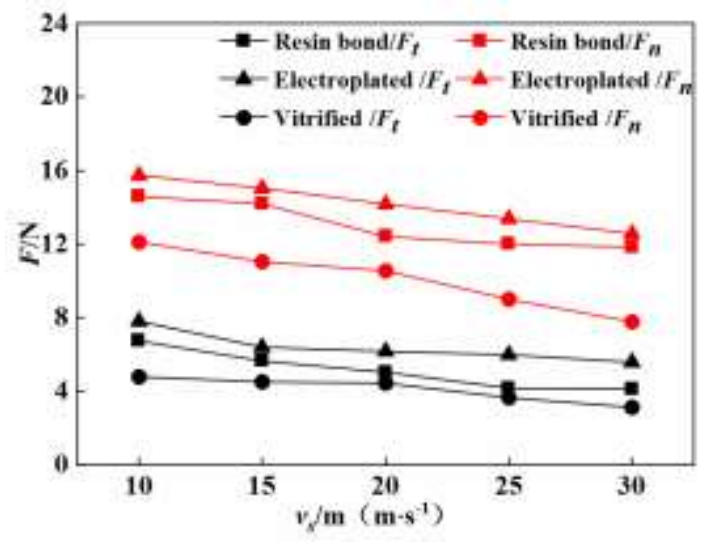

Fig. 20 Effect of grinding wheels on grinding force at different grinding speeds

Fig.21 shows the comparison of grinding forces by electroplated CBN grinding wheel, resin-bonded CBN grinding wheel and vitrified CBN grinding wheel at different grinding depths. It can be seen from Fig.21 that the tangential and normal grinding forces generated by the three kinds of grinding wheels all increase with the increase of grinding depth. Under the same grinding parameters, the grinding force produced by electroplated CBN wheel is greater, the grinding force produced by the resin-bonded CBN grinding wheel is slightly lower than that of the electroplated CBN grinding wheel, and the grinding force produced by vitrified CBN grinding wheel is smaller.

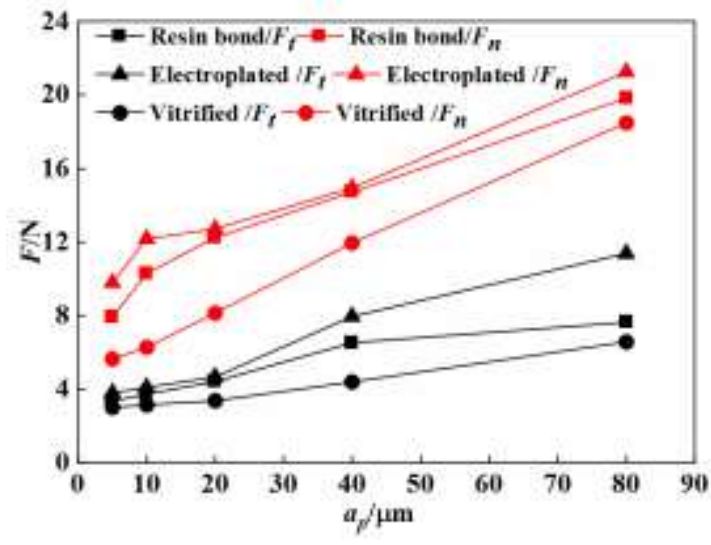


Fig.21 Effect of grinding wheels on grinding force at different grinding depths

From the overall trend, in the grinding process of FeCoNiCrMo ${ }_{0.1}$ HEA, the changing tendency between grinding force and grinding parameters has little relationship with the type of the bonding agent of grinding wheel. However, from the point of view of grinding force value: under the same processing parameters, as the grinding parameters change, the grinding force produced by electroplated CBN grinding wheel is greater, the grinding force generated by the resin-bonded CBN grinding wheel is slightly lower than that of electroplated CBN grinding wheel, and the grinding force produced by vitrified CBN grinding wheel is lower. The reason may be that the vitrified grinding wheel has the advantage of strong self-sharpening, which can keep the sharpness of the grinding edge at all times in the grinding process, so that the cutting edge of the abrasive grain is more easily exposed. The thickness of the undeformed chip of the single abrasive grain of the vitrified grinding wheel is smaller, and the deformation degree of the chip is also smaller, so that the grinding force is lower among the three grinding wheels. At the same time, the vitrified bonding agent has better thermal stability at high temperature, which can promote the thermochemical reaction, so that the heat softening layer is generated on the specimen grinding surface. The materials are easier to be removed, thus the wear of the grinding wheel on the machining surface is reduced. It can be seen that vitrified $\mathrm{CBN}$ grinding wheel has certain advantages in grinding the HEA process, which can improve grinding efficiency, reduce grinding wheel wear and ensure better surface quality.

\subsubsection{Influence law of different materials on grinding force}

The orthogonal grinding experiments of $\mathrm{FeCoNiCrMo}_{0.1}$ and $\mathrm{FeCoNiCrAl}_{0.1}$ HEAs were conducted by using vitrified CBN grinding wheel, and the grinding forces generated by grinding the two kinds of HEAs were compared under the same machining conditions. Fig.22 is the comparison of grinding forces during grinding two kinds of HEAs at different feed speeds. It can be seen from Fig.22 that the tangential and normal grinding forces generated by grinding the two kinds of HEAs both increase with the increase of feed speed. Under the same grinding parameters, the grinding force produced by grinding $\mathrm{FeCoNiCrAl}_{0.1}$ HEA is smaller than that produced by grinding $\mathrm{FeCoNiCrMo}_{0.1}$ HEA.

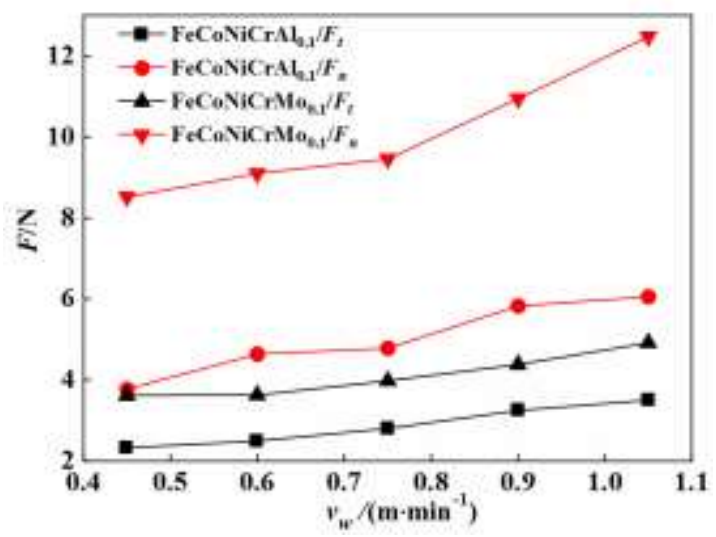

Fig.22 Effect of materials on grinding force of HEAs at different feed speeds

It can be seen from Fig.23, the comparison of grinding forces in grinding two kinds of HEAs at different grinding speeds. As grinding speed increases, tangential and normal grinding forces decrease. In addition, the grinding force produced by grinding $\mathrm{FeCoNiCrAl}_{0.1} \mathrm{HEA}$ is smaller than that produced by grinding $\mathrm{FeCoNiCrMo}_{0.1}$ HEA under the same parameters.

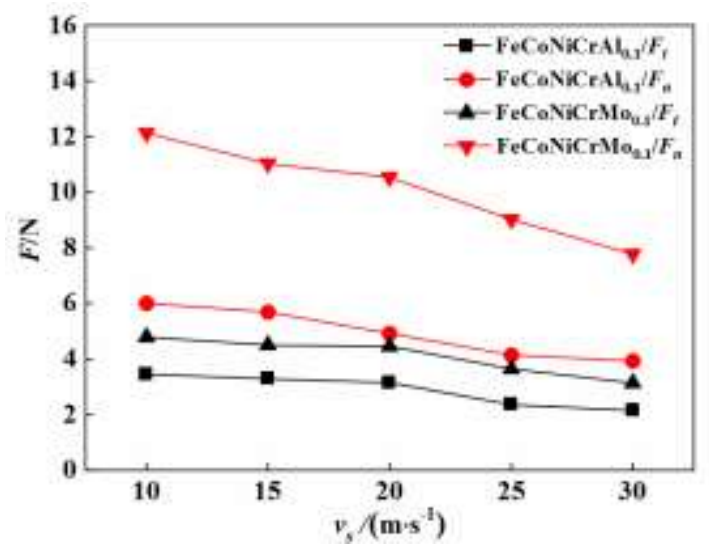

Fig.23 Effect of materials on grinding force of HEAs at different grinding speeds

Fig.24 shows the comparison of grinding forces in 
grinding two kinds of HEAs at different grinding depths. The tangential and normal grinding forces increase with grinding depth increasing. The tangential and normal grinding forces produced by grinding $\mathrm{FeCoNiCrAl}_{0.1}$ HEA are clearly smaller than that produced by grinding $\mathrm{FeCoNiCrMo}_{0.1}$ HEA when the grinding conditions are same.

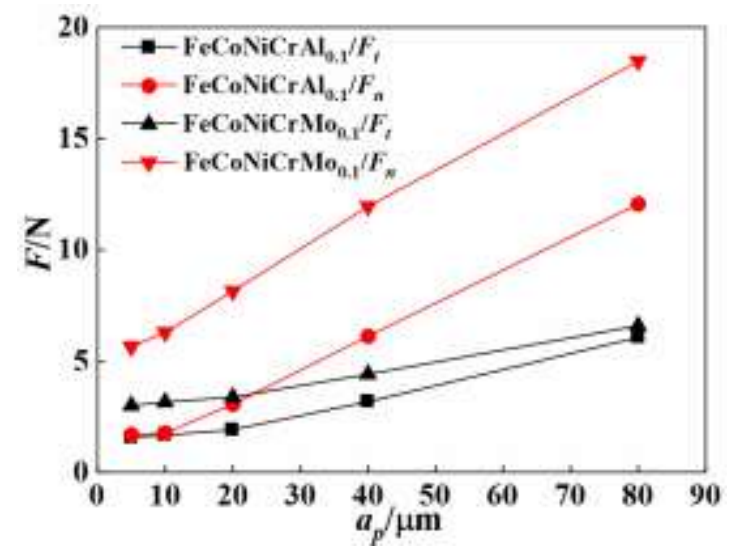

Fig.24 Effect of materials on grinding force of HEAs at different grinding depths

In general, with the change of grinding parameters, the trends of grinding forces by grinding the two kinds of HEAs are similar. For the FeCoNiCr HEAs, the addition of $\mathrm{Al}$ element may promote the phase structure of alloy from FCC phase to BCC phase and the lattice structure from cellular crystal to dendritic crystal, and increase the hardness, strength and the wear resistance and decrease plasticity. However, the addition of Mo element may increase the lattice coefficient of BCC phase of the HEAs, make the microstructure of the alloy obviously refined, and improve the strength, hardness and plasticity. The HEAs used in the experiment were prepared by casting method. According to the research findings [12-13], the phase structure of the two casting HEAs are single FCC phase, and $\mathrm{FeCoNiCrAl}_{0.1}$ HEA has the columnar cell structure, while $\mathrm{FeCoNiCrMo}{ }_{0.1}$ HEA has the typical dendritic structure. The network skeleton structure formed by dendrite phase has a more significant strengthening effect on the alloy than that formed by columnar cell phase. Therefore, the experimental results show that the grinding force generated by grinding $\mathrm{FeCoNiCrMo}_{0.1}$ HEA is higher than that produced by grinding $\mathrm{FeCoNiCrAl}_{0.1}$ HEA.

\subsection{Verification of grinding force model of HEA}

In order to verify the reliability of the HEA grinding force model established in this paper, that theoretical value of grinding force per unit width is multiplied by the actual grinding width can obtain the overall theoretical calculating value. The overall theoretical value of grinding force is compared with the experimental measurement value when the processing parameters are the same, and the theoretical calculating and experimental measured values of $\mathrm{FeCoNiCrMo} 0.1$ HEA are compared as follows.

The first set of single factor experiments verified the correctness of the theoretical model when the grinding force varied with the grinding speed $v_{s}$ changing. Processing parameters: constant value $v_{w}$ $=0.75 \mathrm{~m} / \mathrm{min}, a_{p}=20 \mu \mathrm{m}$, variable $v_{s}=13 \mathrm{~m} / \mathrm{s}, 15 \mathrm{~m} / \mathrm{s}$, $18 \mathrm{~m} / \mathrm{s}, 20 \mathrm{~m} / \mathrm{s}, 23 \mathrm{~m} / \mathrm{s}, 25 \mathrm{~m} / \mathrm{s}$. Comparisons between the experimental measured values and calculating values of the theoretical model are shown in Fig.25 and Fig.26. It can be seen from the figures that the maximum relative error between the theoretical and experimental values of tangential grinding force is $11.20 \%$, and the average relative error is $4.94 \%$. The maximum relative error between the theoretical and experimental values of the normal grinding force is $38.70 \%$ and the average relative error is $25.65 \%$.

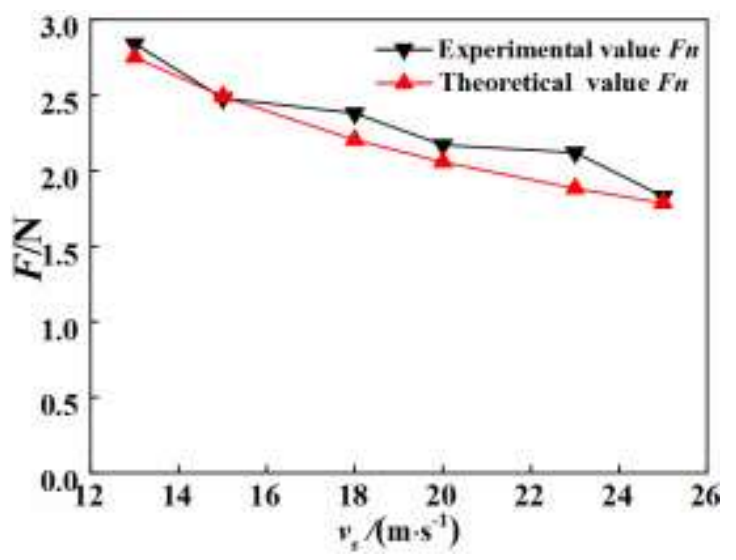

Fig.25 Theoretical and experimental values of tangential grinding forces at different grinding speeds 


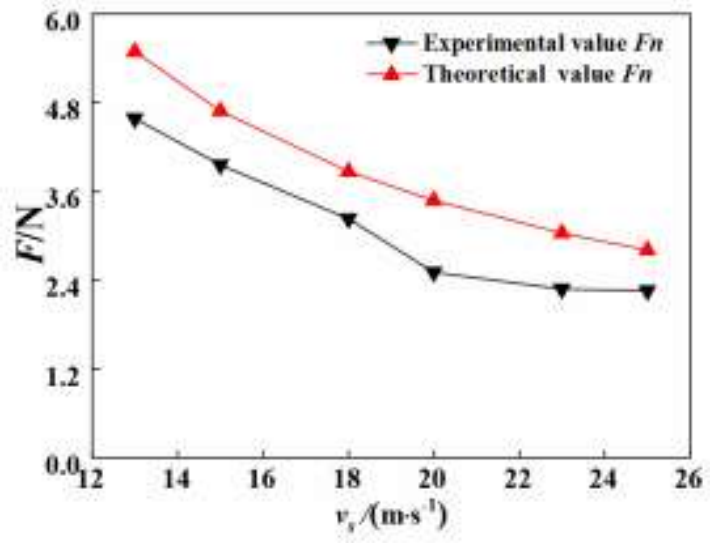

Fig.26 Theoretical and experimental values of normal grinding force of at different grinding speeds

The second set of single factor experiments verified the correctness of the theoretical model when the grinding force changed with the grinding depth $a_{p}$. Processing parameters: constant value $v_{w}=0.75 \mathrm{~m} / \mathrm{min}$, $v_{s}=25 \mathrm{~m} / \mathrm{s}$, variable $a_{p}=30 \mu \mathrm{m}, 40 \mu \mathrm{m}, 50 \mu \mathrm{m}, 60 \mu \mathrm{m}$, $70 \mu \mathrm{m}, 80 \mu \mathrm{m}$. Fig. 27 and Fig. 28 show the comparisons between the experimental measured values and calculating values of the theoretical model. It can be seen from the figures, the maximum relative error between the theoretical and experimental values of tangential grinding force is $5.50 \%$, and the average relative error is $2.32 \% \%$. The maximum relative error between the theoretical and experimental values of the normal grinding force is $13.55 \%$ and the average relative error is $6.41 \%$.

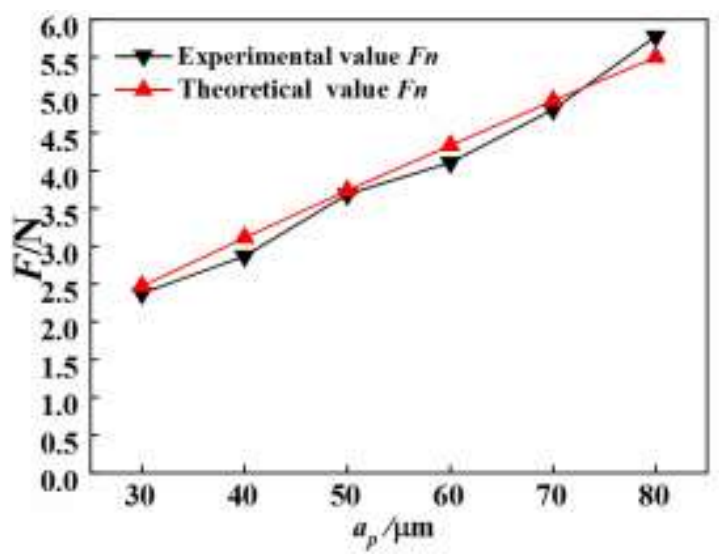

Fig. 27 Theoretical and experimental values of tangential grinding forces at different grinding depths

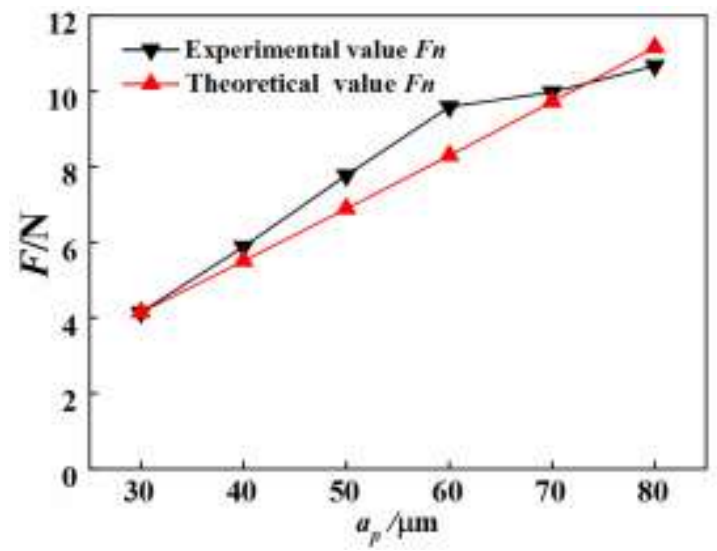

Fig.28 Theoretical and experimental values of normal grinding forces at different grinding depths

According to the comparisons of two sets of experiments, with the change of grinding parameters, the theoretical calculating values of tangential and normal grinding forces are consistent with the experimental measured values, and the theoretical calculating values are within an acceptable range. Analysis of the cause of error: firstly, in the process of deriving the theoretical model of grinding force, the single abrasive grain is simplified to the cone, but the actual single abrasive grain is not standard cone;secondly, when calculating the contact arc length between the specimen and the grinding wheel, the dynamic contact arc length is not the actual contact arc length between the specimen and the grinding wheel; finally, the abrasive grains on the actual grinding wheel are not uniformly distributed, and the protruding height of the abrasive grains is not consistent.

\section{Conclusions}

1) In the grinding process of $\mathrm{FeCoNiCrMo}{ }_{0.1} \mathrm{HEA}$, the grinding debris is mainly banded and block grinding debris and free surface of the grinding debris has the serrated characteristic. The shear slip occurs along the grain boundary and plastic deformation layer is formed in the grinding subsurface. The work hardening phenomenon occurs in the grinding surface. The HEA conforms to the plastic material removal mechanism.

2 ) The grinding force generated by grinding $\mathrm{FeCoNiCrMo}_{0.1}$ HEA decreases with the increase of 
grinding speed and the decrease of grinding depth and feed speed. Meanwhile, as the force decreases, the grinding surface quality of the HEA become better.

3)Under the same grinding parameters, grinding force produced by grinding FeCoNiCrMo ${ }_{0.1}$ HEA with electroplated CBN grinding wheel is greater, the resin-bonded CBN grinding wheel is second, and the vitrified $\mathrm{CBN}$ grinding wheel is smaller. Compared with $\mathrm{FeCoNiCrAl}_{0.1}$ HEA, FeCoNiCrMo ${ }_{0.1}$ HEA produces larger grinding force under the same grinding conditions.

4)The calculated values of HEA grinding force model are consistent with the experimental values, which can scientifically reflect the variation of grinding force.

Availability of data and materials The data generated and analysed during this study are included in this paper.

Authors' contributions Ruchu $\mathrm{Xu}$ has been responsible for writing this paper. Xuelong Wen has been responsible for reviewing this paper and funding acquisition. Yadong Gong has been responsible for offer idea and guidance. Xingchen Yu has been responsible for performing experiments and analyzing data.

Funding information This paper's work is supported by the National Natural Science Foundation of China (No. 51775100) and the Fundamental Research Funds for the Central Universities (No. N2103023).

Code availability Not applicable.

Declarations

Ethics approval Not applicable.

Consent to participate Not applicable.

Consent for publication Not applicable

Conflicts of interest The authors declared that they have no conflict of interest.

\section{References}

1. Yeh JW, Chen SK, Lin SJ, Gan JY, Chin TS, Shun TT, Tsau CH, Chang SY (2004). Nanostructured high-entropy alloys with multiple principal elements:novel alloy design concepts and outcomes. Advanced Engineering Materials 6(5):299-303.https://doi.org/10.1002/adem.20030
0567

2. Liu Y, Gong YD, Zhang H, Sun Y, Cai M (2018) Experimental investigations into grinding characteristics of high entropy alloys (HEAs) using micro grinding. Int $\mathbf{J}$ Adv Manuf Technol 96:4477-4499.https://doi.org/10.1007/s00170-08 $-1726-2$

3. He JY, Liu WH, Wang H, Wu Y, Liu HJ, Nieh TG, Lu ZP (2014) Effects of Al addition on structural evolution and tensile properties of the FeCoNiCrMn high-entropy alloy system. Acta Materialia 62:105-113.https://doi.org/10.1016/j. actamat.2013.09.037

4. Nie XW, Cai MD, Cai S (2021) Microstructure and mechanical properties of a novel refractory high entropy alloy HfMoScTaZr. International Journal of Refractory Metals and Hard Materials 98:1-9.https://doi.org/10.1016/j.ijrmhm.2021.105 568

5. Shen QK, Kong XD, Chen XZ (2021) Fabrication of bulk Al-Co-Cr-Fe-Ni high-entropy alloy using combined cable wire arc additive manufacturing (CCW-AAM):Microstructure and mechanical properities. Journal of Materials Science \& Technology74:136-142.https://doi.org/10.1016/j.j mst.2020. 10.037

6. Nhung TC N, Peyman AR, Praveen S, Alireza Z, Chong SL, Hyoung SK (2020) Ultrahigh high-strain-rate superplasticity in a nanostructured high-entropy alloy. Nature Communications11(1):2736.https://doi.org/10.10 38/s41467-020-16601-1

7. Senkov ON, Wilks GB, Scott JM, Miracle DB (2011) Mechanical properties of $\mathrm{Nb}_{25} \mathrm{Mo}_{25} \mathrm{Ta}_{25} \mathrm{~W}_{25}$ and $\mathrm{V}_{20} \mathrm{Nb}_{20} \mathrm{Mo}_{20} \mathrm{Ta}_{20}-\mathrm{W}_{20}$ refractory high entropy alloys. Intermetallics 19(5):698-706.https://doi.org/10.1016/j.intermet. 2011.01.004

8. Lu YP, Huang HF, Gao XZ, Ren CL, Gao J, Zhang HZ, Zheng SJ, Jin QQ, Zhao YH, Lu CY, Wang TM, Li TJ (2019) A promising new class of irradiation tolerant materials: $\mathrm{Ti}_{2} \mathrm{ZrHfV}_{0.5} \mathrm{Mo}_{0.2}$ high-entropy alloy. Journal of Materials Science \& Technology 35( 3):369-373. https://doi.org/ 
10.1016/j.jmst.2018.09.034

9. George C, Emilia B, Ionelia V, Victor G, Valentin C (2020) Cutting behavior of $\mathrm{Al}_{0.6} \mathrm{CoCrFeNi}$ high entropy alloy. Materials 13(18):4181. https:// doi.org/10.3390/ma13184181

10. Przemyslaw L, Everth HN, Dikai G, Russell G, Krystian KW (2021) The additive manufacture processing and machinability of $\mathrm{CrMnFeCoNi}$ high entropy alloy. Materials \& Design 198:1-14. https://doi.org/10.1016/j.matdes.2020.109380

11. Zhou YG, Ma LJ, Gong YD, Zhang L, Yin GQ, Sun Y (2019) Study on the mechanism of chip forming and the microhardness of micro-grinding nickel-based single-crystal superalloy. Int J Adv Manuf Technol 103:281-295. https://doi.org/ 10.1007/s00170-019-03503-w

12. Kao YF, Chen TJ, Chen SK, Yeh JW (2009) Microstructure and mechanical property of as-cast, -homogenized, and -deformed $\mathrm{Al}_{\mathrm{x}} \mathrm{CoCrFeNi}(0 \leqslant \mathrm{x} \leqslant 2)$ high-entropy alloys. Journal of Alloya \& Compounds 488(1):57-64. https://doi.org/10.1016/j.jallcom.2009.08.090

13. Dai CD, Zhao TL, Du CW, Liu ZY, Zhang DW (2020) Effect of molybdenum content on the microstructure and corrosion behavior of $\mathrm{FeCoCrNiMo}_{x}$ high-entropy alloys. Journal of Materials Science \& Technology 46:64-73. https://doi.org/10.1016/j.jmst.2019.10.020 